\title{
ANALYSIS OF OPTIMAL PROCESS FLOW DIAGRAMS OF LIGHT NAPHTHA ISOMERIZATION PROCESS BY MATHEMATIC MODELLING METHOD
}

\author{
Vjacheslav Chuzlov ${ }^{1, *}$, Konstantin Molotov ${ }^{2}$ \\ ${ }^{1}$ Tomsk Polytechnic University, Lenin av. 30, Tomsk, 634050, Russia \\ ${ }^{2} \mathrm{OOO}$ “Kinef”, Enthusiastov Highway 1, Kirishi, Russia;
}

\begin{abstract}
An approach to simulation of hydrocarbons refining processes catalytic reactors. The kinetic and thermodynamic research of light naphtha isomerization process was conducted. The kinetic parameters of hydrocarbon feedstock chemical conversion on different types of platinumcontent catalysts was established. The estimation of efficiency of including different types of isomerization technologies in oil refinery flow diagram was performed.
\end{abstract}

\section{Introduction}

The increase of straight run normal alkanes $\mathrm{C}_{5}-\mathrm{C}_{6}$ fraction research octane rating to 92 points is an effective decision of important applied problem of changing the structure of native gasoline pool. The high octane flow of isomerate does not content a sulfur, aromatic and olefin hydrocarbon that is why it is an excellent component for finished gasoline compounding. The selection of optimal process flow diagram (PFD) of light naphtha isomerization is an important research and practice task which can be solved more efficiently with a help of mathematical modelling method.

\section{Research Object}

In this paper the research object is catalytic isomerization of light gasoline fraction unit on sulfated catalyst with different recycle flows direction (figure 1) and isomerization unit with recycle of unconverted hexanes on chlorinated Pt-content catalyst (figure. 2).

\footnotetext{
* Corresponding author: chuva@tpu.ru
} 


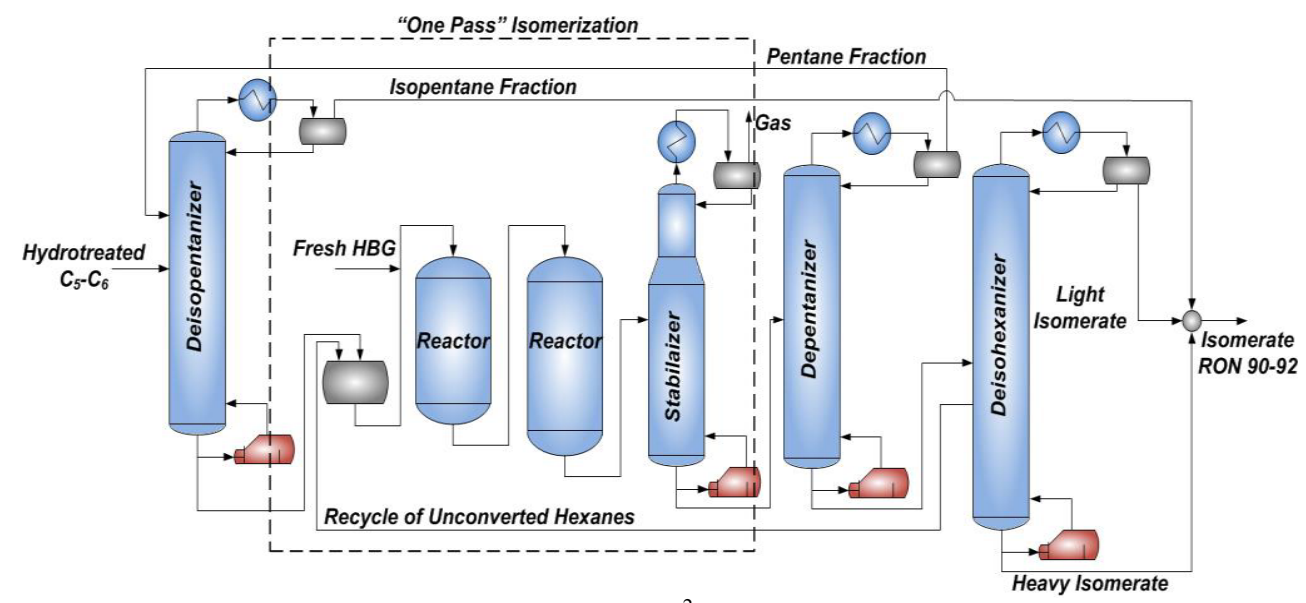

Fig. 1. Light naphtha isomerization $\mathrm{PFD}$ on $\mathrm{Pt} / \mathrm{SO}_{4}{ }^{2-} / \mathrm{ZrO}_{2}$ catalyst "One pass" and with recycles of $\mathrm{n}-\mathrm{C}_{5}$ and unconverted hexanes

Isomerization catalysts based on sulfated metal oxides combines high activity and resistance to poisons and have ability to regeneration [1-3]. "One pass" isomerization technology is the simplest, has minimal capital and operation costs and provides the production of isomerate with 80-82 RON. Including in "one pass" isomerization recycles of unconverted $\mathrm{C}_{5}-\mathrm{C}_{6}$ hydrocarbons takes more difficult conditions of its operation but helps to reach the increase in RON about 10-12 points.

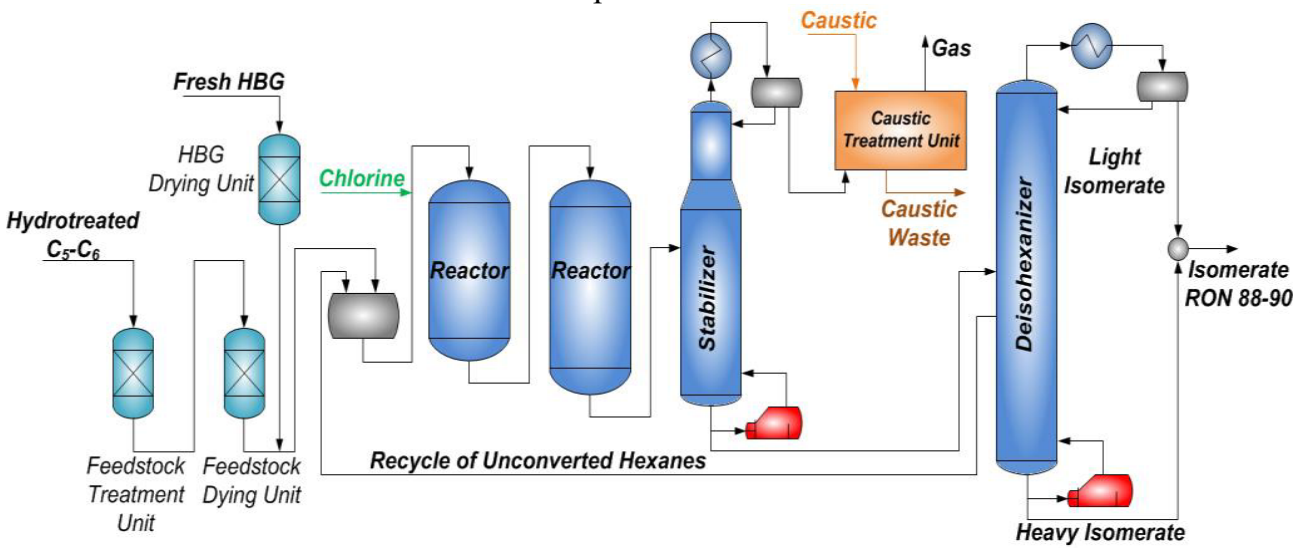

Fig. 2. Light naphtha isomerization $\mathrm{PFD}$ on $\mathrm{Pt} / \mathrm{Cl}^{-} / \mathrm{Al}_{2} \mathrm{O}_{3}$ catalyst with recycle of unconverted hexanes

Catalysts based on chlorinated alumina oxide due to longtime operation lose chlorine. In result its activity is decreased. In addition it requires a caustic treatment unit to utilize organic chlorine. Chlorinated catalyst can't be regenerated and its operation cycle is 3-5 years.

\section{Methods}

In this paper for description of unsteady catalytic processes of hydrocarbon feedstock isomerization the method of mathematical modelling is used. According to characterized methodology [4-15] the construction of mathematical model of complicated chemicalengineering process consist in sequential implementation of following stages: conducting of thermodynamic analysis, estimation of kinetic parameters of thermodynamically possible reactions, construction of reactor model and chemical-engineering system at all. 
The full mathematical description of hydrocarbon feedstock catalytic isomerization process is formatted on components material and heat balances:

$$
\left\{\begin{array}{l}
G \cdot \frac{\partial C_{i}}{\partial z}+G \cdot \frac{\partial C_{i}}{\partial V}=\sum_{j=1}^{m} a_{j} \cdot r_{j} \\
\frac{\partial T}{\partial z}+G \cdot \frac{\partial T}{\partial V}=\sum_{j=1}^{m} a_{j} \cdot r_{j} \cdot \Delta H_{j}
\end{array}\right.
$$

if $\mathrm{Z}=0, \mathrm{C}=0$, where $\mathrm{r}=0, \mathrm{C}=\mathrm{C}_{0}$, if $\mathrm{Z}=0, \mathrm{~T}=\mathrm{T}_{0}$, where $\mathrm{r}=0, \mathrm{~T}=\mathrm{Tin}$;

where $G$ is a feedstock flow rate, $\mathrm{m}^{3} / \mathrm{h} ; \mathrm{z}=\mathrm{G}^{*} \mathrm{t}(\mathrm{t}$ is a overall time of catalyst work starting from the new catalyst load, $\mathrm{h}$ ); $\mathrm{Ci}$ is a concentration of ith component, $\mathrm{mol} / \mathrm{m}^{3} ; \mathrm{V}$ is a volume of the catalyst bed, $\mathrm{m}^{3}$; $\mathrm{a}$ is a catalyst activity; $\rho$ is density of hydrocarbon mixture, $\mathrm{kg} / \mathrm{m}^{3} ; \mathrm{Cmp}$ is a specific heat capacity of hydrocarbon mixture, $\mathrm{J} /(\mathrm{kg} * \mathrm{~K}) ; \mathrm{Q}_{\mathrm{j}}$ is jth reaction heat, $\mathrm{J} / \mathrm{mol}$, T is temperature, $\mathrm{K} ; \mathrm{rj}$ is jth reaction rate, $\mathrm{mol} /\left(\mathrm{m}^{3} \mathrm{~h}\right)$, a - activity of catalyst.

The program realization of this model is implemented in Delphi 7. The initial data for calculation are feedstock composition and operation parameters of the process. The adequacy of the model is estimated by comparison of experimental data from industrial isomerization plant with calculated values [10]. The activity of catalyst is decreased due to processes of coke formation, poisoning and ageing.

\section{Results and Discussion}

The research of kinetic parameters of purposeful reactions of light naphtha isomerization process for chlorinated and sulfated catalysts is presented in table 1 .

Table 1. The comparison of major reactions kinetic parameters of isomerization process

\begin{tabular}{|c|c|c|}
\hline \multirow{2}{*}{ Reactions } & \multicolumn{2}{|c|}{ Relative rate constants } \\
\cline { 2 - 3 } & $\mathrm{Pt}_{\mathrm{SO}_{4}{ }^{2-} / \mathrm{ZrO}_{2}}$ & $\mathrm{Pt} / \mathrm{Cl}^{-} / \mathrm{Al}_{2} \mathrm{O}_{3}$ \\
\hline $\mathrm{n}-\mathrm{C}_{5} \rightarrow \mathrm{i}-\mathrm{C}_{5}$ & 1 & 0.31 \\
\hline $\mathrm{i}-\mathrm{C}_{5} \rightarrow \mathrm{n}-\mathrm{C}_{5}$ & 1 & 0.96 \\
\hline $\mathrm{nC}_{6} \rightarrow 2$ Methylpentane & 1 & 0.47 \\
\hline 2Methylpentane $\rightarrow 2.3$ Dimethylbutane & 1 & 0.16 \\
\hline 2Methylpentane $\rightarrow 3$ Methylpentane & 1 & 1.72 \\
\hline 2.2 Dimethylbutane $\rightarrow 2.3$ Dimethylbutane & 1 & 0.85 \\
\hline
\end{tabular}

Rate constants of major reactions for sulfated catalyst are taken as 1, rate constants for chlorinated catalyst are performed as a part of 1 . In such a way major reactions of isomerization process pass faster on sulfated catalyst.

The isomerate composition for different light straight run cuts isomerization technologies is presented in table 2 .

Table 2. Calculated isomerate composition 


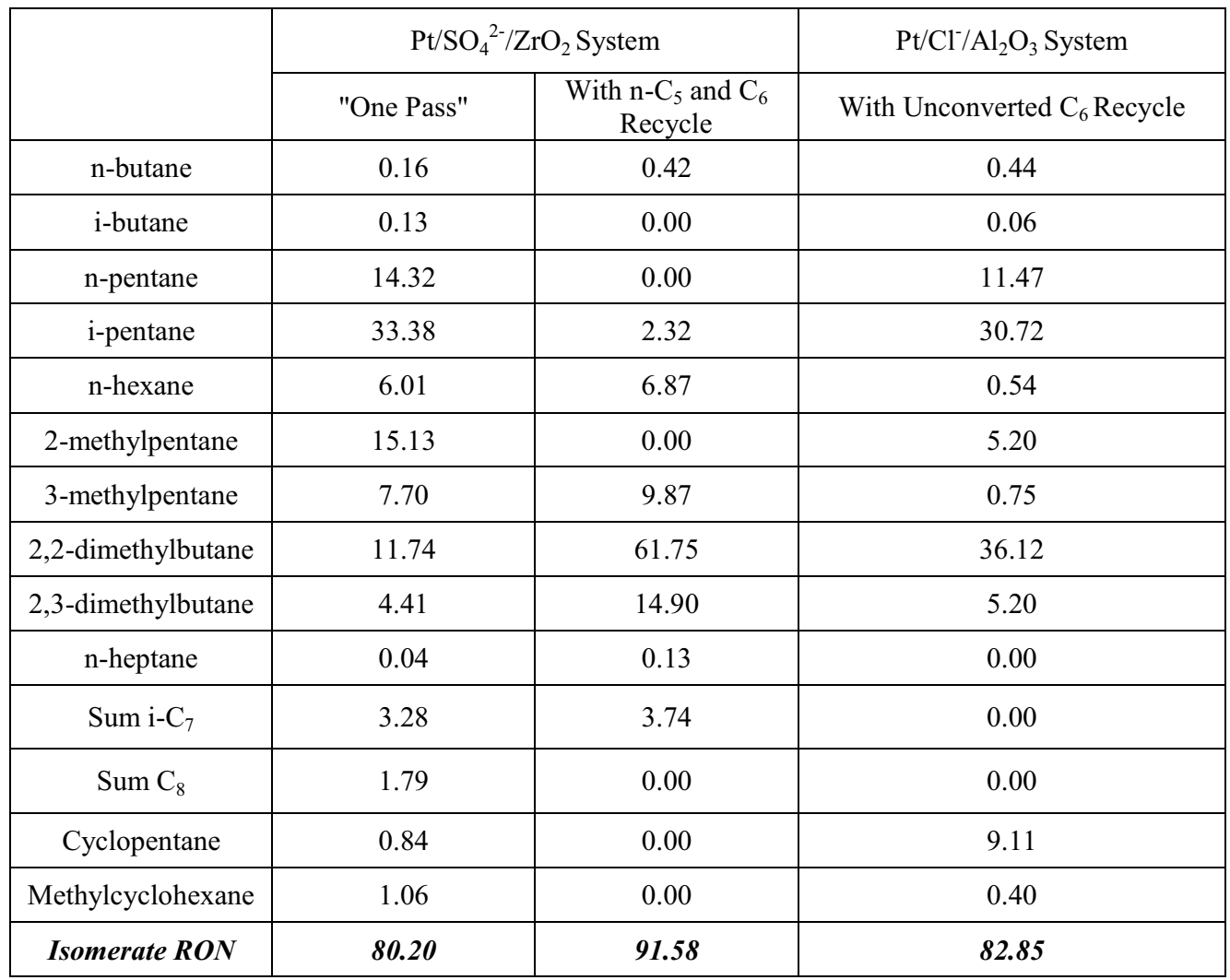

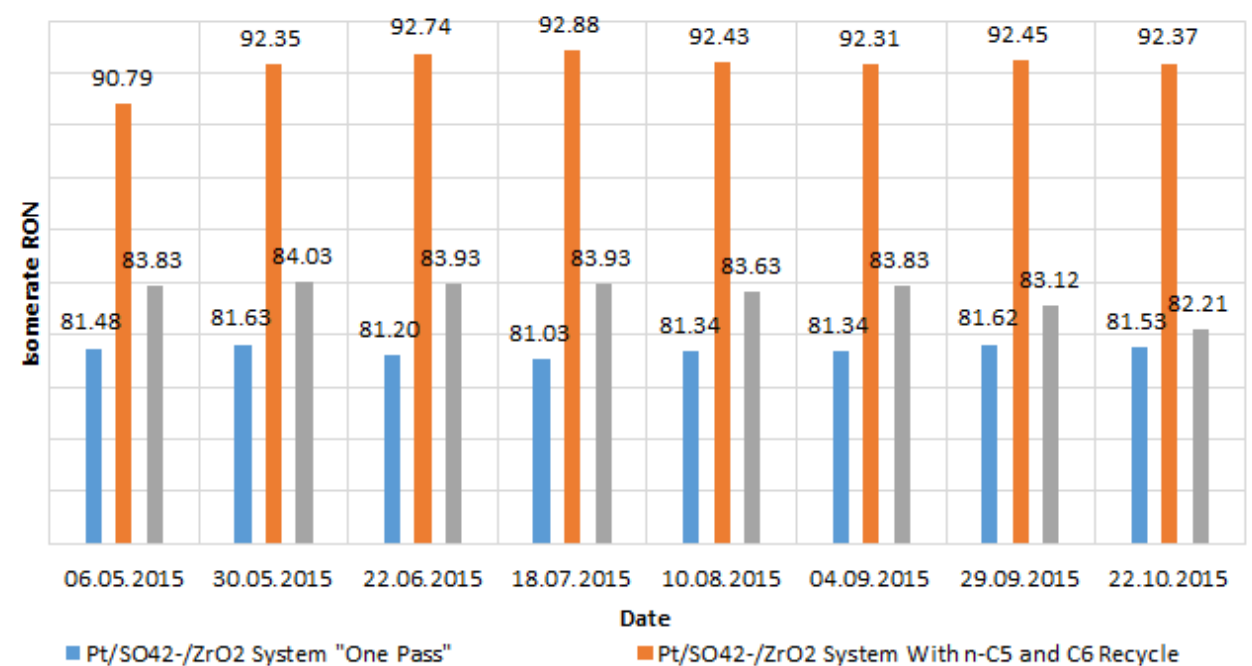

n Pt/Cl-/Al2O3 System With Unconverted C6 Recycle

Fig. 3. Isomerate RON vs different types of catalyst and PFD

Application of catalyst based on sulfated zirconia in industrial isomerization process with recycles of unconverted hydrocarbons C5-C6 allows to produce isomerate with RON 10-12 points higher than traditional "one pass" isomerization technology and with RON 8-9 
points higher than technology based on chlorinated catalyst with unconverted $\mathrm{C}_{6}$ hydrocarbons recycle (figure 3).

\section{References}

1. Shakun A.N., Fedorova, M.L. Isomerization of light gasoline fractions: The efficiency of different catalysts and technologies, Catal. Ind., 6(4), 298-306, (2014)

2. Shakun, A., Aranovich, I., Reis, E. Isomalk-2: A low-temperature, light naphtha isomerization process, 2012 12AIChE - 2012 AIChE Spring Meeting and 8th Global Congress on Process Safety, Conference Proceedings

3. Shakun, A.N., Yas'yan, Yu.P., Litvinova, S.M. Some stability aspects of new zeolite containing catalysts for selective hydrocracking, Khimiya i Tekhnologiya Topliv i Masel, 2, 39-40, (2001)

4. Frantsina, E.V., Ivashkina, E.N., Ivanchina, E.D., Romanovskii, R.V. Developing of the mathematical model for controlling the operation of alkane dehydrogenation catalyst in production of linear alkyl benzene, Chem. Eng. J., 238, 129-139, (2014)

5. Kravtsov A.V., Ivanchina E.D., Ivashkina E.N., Frantsina E.V., Kiselyova S.V., Romanovsky R.V. Thermodynamic Stability of Coke-Generating Compounds Formed on the Surface of Platinum Dehydrogenation Catalysts in Their Oxidation with Water, Pet. Chem., 53, 267-275, (2013)

6. Dolganova I.O., Dolganov I.M., Ivashkina E.N., Ivanchina E. D., Romanovsky R. V. Development of Approach to modelling and optimization of non-stationary catalytic processes in oil refining and petrochemistry, Pol. J. Chem. Technol., 14(4), 22-29 (2012)

7. Ivashkina E.N., Frantsina E.V., Romanovsky R.V., Dolganov I.M., Ivanchina E. D., Kravtsov A.V. Developing a Method for Increasing the Service Life of a Higher Paraffin Dehydrogenation Catalyst, Based on the Nonstationary Kinetic Model of a Reactor, Catal. Ind., 4(2), 110-120, (2012)

8. Dolganova I.O., Dolganov I.M., Ivashkina E.N., Ivanchina E.D. Development of computer modeling system as a tool for improvement of linear alkylbenzene production, Pet. Coal, 53, 244-250, (2011)

9. Ivashkina E.N., Youriev E.M., Ivanchina E.D., Kravtsov A.V., Frantsina E.V., Romanovskiy R.V. Development of an intelligent system for controlling paraffin dehydrogenation catalyst operation in production of linear alkyl benzenes, Catal. Ind., 2(2), 137-144, (2010)

10. Chekantsev N.V., Gyngazova M.S., Ivanchina E.D., Mathematical modeling of light naphtha (C5, C6) isomerization process, Chem. Eng. J., 238, 120-128, (2014)

11. Ivanchina, E., Ivashkina, E.,Frantsina, E., Silko, G., Kiseleva, S.Determination of the optimal operation mode of the platinum dehydrogenation catalysts // Advanced Materials Research, 880, 25-31, (2014)

12. Nazarova, G.Y., Ivashkina, E.N.,Ivanchina, E.D., Stebeneva, V.I.,Seytenova, G.Z.Effect of Group Composition of the Vacuum Distillate from Heavy Kazakhstan and West Siberian Oil on the Yield of Light Fractions during the Catalytic Cracking // Procedia Engineering, 152, 18-24, (2016)

13. .S. Belinskaya, E.D. Ivanchina, E.N. Ivashkina, V.A. Chuzlov, S.A. Faleev. Mathematical modeling of the process of catalytic hydrodewaxing of atmosheric gasoil considering the interconnection of the technological scheme devices // Procedia Engineering, 113, 68-72, (2015)

14. Belinskaya N.S., Ivanchina E.D., Ivashkina E.N., Silko G.Y. Effect of feed composition changing at naphtha catalytic reforming unit due to involvement of gasoline fraction obtained by diesel fuels hydrodewaxing into the processing // Procedia 
Chemistry, 10, 267-270, (2014)

15. N.S. Belinskaya Mathematical modelling and optimization of catalytic dewaxing of diesel oil cuts and atmosheric gas oil // Peteroleum and Coal, 58(1), 126-134, (2016) 